\title{
Gender and political orientation in childhood
}

Nicholas Alozie

James L. Simon

Fairfield University, jsimon@fairfield.edu

Bruce D. Merrill

Follow this and additional works at: https://digitalcommons.fairfield.edu/english-facultypubs

Copyright 2003 Elsevier

NOTICE: this is the author's version of a work that was accepted for publication in The Social Science Journal. Changes resulting from the publishing process, such as peer review, editing, corrections, structural formatting, and other quality control mechanisms may not be reflected in this document. Changes may have been made to this work since it was submitted for publication. A definitive version was subsequently published in The Social Science Journal, 40(1), 1-18. DOI: 10.1016/S0362-3319(02)00255-0

\section{Peer Reviewed}

\section{Repository Citation}

Alozie, Nicholas; Simon, James L.; and Merrill, Bruce D., "Gender and political orientation in childhood" (2003). English Faculty Publications. 58.

https://digitalcommons.fairfield.edu/english-facultypubs/58

\section{Published Citation}

Alozie, Nicholas; Simon, James \& Merrill, Bruce D. (2003). "Gender and political orientation in childhood." The Social Science Journal, 40(1), 1-18.

This item has been accepted for inclusion in DigitalCommons@Fairfield by an authorized administrator of DigitalCommons@Fairfield. It is brought to you by DigitalCommons@Fairfield with permission from the rightsholder(s) and is protected by copyright and/or related rights. You are free to use this item in any way that is permitted by the copyright and related rights legislation that applies to your use. For other uses, you need to obtain permission from the rights-holder(s) directly, unless additional rights are indicated by a Creative Commons license in the record and/or on the work itself. For more information, please contact digitalcommons@fairfield.edu. 


\section{Gender And Political Orientation in Childhood}

\section{Nicholas O. Alozie}

Associate Professor

School of Public Affairs

Arizona State University

Box 870603

Tempe, Arizona 85287-0603

Phone: (480) 965-0122

Fax: (480) 965-9248

E-mail: Alozie@Asu.Edu.

\section{James Simon}

Assistant Professor

Department of English

Fairfield University

North Benson Road

Fairfield, Connecticut 06430-5195

Phone: (203) 254-4000 x2792

E-Mail: jsimon@fairl.fairfield.edu

\section{Bruce D. Merrill}

Professor and Director, Media Research Program

Walter Cronkite School of Journalism And Telecommunication

Arizona State University

Box 871305

Tempe, Arizona 85287-1305

Phone: (480) 965-7051

E-mail: atbdm@asuvm.inre. asu.edu

Direct all correspondence to Nicholas Alozie, School of Public Affairs, Arizona State University, Box 870603, Tempe, Arizona 85287-0603 (e-mail: Alozie@asu.edu). A previous version of this manuscript was delivered at the 1998 Annual Meeting of the Western Political Science Association, Los Angeles, California, March. We thank Susan J. Carroll, Warren E. Miller (deceased), Heather Campbell, Robert Benedetti, and Syd Goldstein of the Kids Voting USA program for their helpful comments on earlier drafts of this manuscript. 


\title{
Gender And Political Orientation in Childhood
}

\begin{abstract}
The precept that boys are more political than girls has had enormous ramifications for the development of the literature of political behavior and, some would contend, the epistemological foundations of the discipline of political science (Carroll and Zerilli, 1993). This study explores whether boys and girls differ in their levels of political orientation and the extent, if at all, race/ethnic heritage mediates such an association. We analyze survey data for 14,855 children across 20 states using a fixed-effects analytical technique that confines the children to their immediate environments. We find that girls surpass boys in political interest and activity, and this persists without a significant drop in teen years as might be expected. This pattern is evident whether political orientation is measured as a composite indicator or as discrete items tapping specific activities and opinions. Within subgroups, white and Native American girls consistently displayed higher levels of orientation than comparable boys. Among black, Hispanic, and Asian Americans, observed advantages for girls attenuate with full specification of control variables; at worst, black, Hispanic, and Asian girls are equally as political as comparable boys. These findings have implications for theorizing about political orientation in childhood.
\end{abstract}

The question of whether boys and girls differ in their political orientation has had enormous ramifications for the development of the literature of political behavior and, some would contend, the epistemological foundations of the discipline of political science (Carroll and Zerilli, 1993). Research conducted through the 1960s and 1970s generally reported that girls are both less interested in politics and less likely to possess politically relevant information (see reviews in Owen and Dennis, 1988; Sapiro, 1983 :3 8). While a variety of structural and contextual explanations, including 
the impact of biological differences, is often advanced for gender differences in political orientation (e.g., Verba, Schlozman, and Brady, 1995; Carroll, 1994; Darcy, Welch, and Clark, 1994; Thomas, 1994; Welch and Sigelman, 1989; Welch, 1978, 1977; Kirkpatrick, 1974), the most enduring explanation for differences in political orientation in childhood stresses gender role socialization (Carroll, 1994: chapter 2, Note 10). Essentially, boys and girls are socialized differently (Lips, 1995; Gilligan, 1982), and girls actively are socialized away from endeavors such as politics that are widely perceived as a "man's game" (Sherkat and Blocker, 1994). ${ }^{1}$

With the onset of feminism and the women's movement in the 1970s, some evidence suggested that gender differences in the political interest of boys and girls were narrowing (Owen and Dennis, 1988; Rapoport, 1985). Much of this research is decades old now, and not nearly enough is known about gender-related political differences in childhood in the early feminist era because research on childhood political differences and on the secondary consequences of gendered political socialization is sparse. Moreover, there have been pointed critiques of the earliest literature, suggesting a male bias in methodology which showcased boys as political and girls as apolitical (see e.g., Welch, 1977; Bourque and Grossholtz, 1974; Iglitzin, 1974).

In the last three decades, political activity by women's groups has increased and become more prominent (Conway, Ahern, and Steuernagel, 1995; Hartmann, 1989; Conover, 1988; Sapiro, 1986). There has been a persistent challenge to the core of a patriarchal culture that nurtured male domination of the political and social system (Clinton, 1999; Langer, 1996; Henry, 1991). Much of the struggle has been waged in courtrooms and policy institutions (e.g., Title IX of the Educational Amendments of 1972 bans sex discrimination in schools, whether it be in academics or athletics.) Salient policy issues-the "glass ceiling," sexual harassment, traditional all-male institutions, women 
in the military, and equal pay for equal work-occupy the headlines. Some of the more potent transformations began at the grassroots level in traditional institutions of socialization such as the family, schools, and churches (Gerber, et al., 1974).

Several salient factors come together to warrant a new look at political differences in childhood. First, there are the expansive and penetrating effects of the feminist movement (see Langer, 1996; Conway, Ahern, and Steuernagel, 1995; Githens and Prestage, 1977). The feminist movement contributed to the current emphasis on the changed roles for women in society (Kahn, 1995; Bozeman, Thornton, and McKinney, 1977). Also, it has contributed to a re-evaluation of some of the fundamental assumptions about child socialization. Second, there is the recurrent theme that the gender gap in political orientation will waver over time due to changes in socialization and accompanying generational replacement (Abramson and Inglehart, 1992; Bennett and Bennett, 1989; Rapoport, 1982, 1985). Finally, the differing emphases on child socialization across racial and ethnic groups could exacerbate gender differences in childhood political orientation (Almquist, 1984).

Our research focuses on two dimensions of the broader question of political differences in childhood: (1) whether boys and girls in the 1990s differed in their levels of political orientation; and (2) the extent to which race/ethnic subculture mediated any differences. Against this background, we test three general hypotheses that are at the core of differences in political orientation in childhood: (1) generally, boys will exhibit higher levels of political orientation than girls; however, that gap will not be as high as those reported previously; (2) white children will exhibit a higher level of political orientation than children from racial and ethnic minority subcultures; and (3) boys and girls within particular racial/ethnic categories will differ in their levels of political orientation.

We utilize a unique data set based on a survey of nearly 15,000 schoolchildren who had been 
exposed to the Kids Voting project in their schools in 20 different states. The data set contains unusually large numbers of Asian, black, Hispanic, and Native American children and affords an opportunity to explore the intersection of gender, race/ethnicity and orientation. Moreover, the data set contains response items of the kind suggested by critiques of the earliest literature of political orientation in childhood in two important respects. First, the response items are not interpretive, precluding cultural assumptions and stereotyping in weighing levels of political orientation. Second, our response items pertain specifically to children's own lives and immediate domains. Accordingly, one can expect these items to resonate much better with the children and to tap their levels of orientation more effectively.

\section{Data And Methods}

To explore gender-related political differences in childhood and the potential mediating influence of race/ethnicity, we analyze data collected by Kids Voting USA in 1994. The Kids Voting program (KV) was initiated in 1988 by three Arizona residents seeking to develop political interest in children early in their lives. The assumption was that early childhood political orientation would spur political activity in adulthood. KV encourages students to seek political information and to cast a mock ballot on election day at polling precincts, accompanied by the adults in their lives.

In 1994, KV made available to teachers a separate six-week curriculum that generally covered two grades (e.g., a curriculum for grades 9-10, or 11-12) and was geared to students' ability levels. The emphasis was on active, hands-on participatory activities, rather than more philosophical discussions about voting. Individual lessons focused on who can vote, the mechanics of voting, how to make informed vote decisions, how to use the news media, why people form political parties, and other content as suitable to each grade level. Most students accompanied their parents to the polls 
and cast a mock election ballot; the results were tabulated comparing the children's choices to those of their parents. An entire school district would decide whether to participate, but delivery of the curriculum was relegated completely to each teacher.

The program expanded to 20 states plus the District of Columbia in 1994. The states were primarily in the South, Midwest and West. ${ }^{2} \mathrm{KV}$ was used by 2.3 million students in kindergarten through grade 12 at a budgeted cost of $\$ 5$ million in cash and in-kind contributions. Community-wide activities such as a "KidsConvention" for students to discuss political issues, the recruitment of hundreds of adult volunteers to handle children's voting booths on election day, and intense media coverage made KV enormously popular in many areas where it was initiated. (In 1996, 4.5 million students in 40 states participated.)

The data set we analyze consists of survey results from 14,855 students in grades 4 through 12, collected by KV from the 20 states that participated in KV in 1994. Multi-cluster sampling generated the students surveyed. Participating schools first were stratified by state, then by racial, and economic characteristics, then selected at random. Individual classes in the 199 chosen schools were then selected at random from class strata of 4-6 and 7-12 grades. This last strategy ensured a broader distribution of students at particular grade levels. All students in a chosen class completed a questionnaire. The survey generated 7,289 responses from grades 4-6 and 7,566 from grades 7-12.

\section{Measuring Political Orientation}

Nine questions were used to gauge the level of political interest and activity. Political interest and activity were combined as an indication of Political Orientation. Two questions tapped each child's conception of civic duty and political efficacy (Did you go to the polls and vote on election day? ${ }^{3}$ How important is it for people to vote on election day?). Two questions measured political 
orientation at school (When political and social issues are debated at your school, do you participate in those discussions? Would you like to have Kids Voting as part of what you learned in school the next time there was an election?). One question assessed political orientation at home (Did you ask questions about voting at home?). The final four questions measured the use of the mass media to seek political information (How often did you watch things about voting on TV? How often did you read things in the newspaper about voting? How often did you hear things about voting on the radio? How often did you read things about voting in magazines?). Whereas prior research asked if children would vote when they became adults, we measured actual participation in voting-related activity.

We computed an index of political orientation for each child by accumulating scores across response categories. ${ }^{4}$ The resulting index arrayed respondents from a possible low score of zero points to a maximum of nine points (mean=6.1, sd--1.9). The index was utilized as our primary dependent variable, capturing the students' overall level of orientation. Men and women may vary in the particular political activities they undertake (Schlozman, et al., 1995); thus, we also explored potential variations between boys and girls in the nine individual items of orientation. Questions relating to these nine items were specified as separate dependent variables.

\section{Influences on Childhood Political Orientation}

\section{The Mediating Effect of Race/Ethnic Subculture}

Scholars who study the impact of culture on different aspects of human development have reached consensus on three major propositions. The first is that America's children are exposed differentially to diverse cultures in their socialization (see literature in Peters, 1997). The second is that racial and ethnic subcultures (as a residual variable beyond socioeconomic status) inculcate socially relevant belief systems into their members (Boykin and Ellison, 1995; Greeley, 1975). The 
third is that these belief systems converge to orchestrate in part the environment for early childhood socialization (Jackson, McCullough, and Gurin, 1997; Peters, 1997). Except for the early effort by Orum, et al. (1974) comparing black and white children, there is no large-scale study of the extent to which sub-cultural variations may account for any differences in political orientation in childhood across cultural groups on the one hand, and between boys and girls in the same group on the other. This is a significant vacuum in this literature given that subculture, reinforced by persistent patterns of residential segregation (Massey and Denton, 1993), remains salient in childhood socialization (Tatum, 1997). Indeed, since children are not subject to factors such as occupational and family (marital/maternal) status that directly impact adult political roles (Greenstein, 1961), sub-cultural belief systems become even more important.

Our interest centers on two separate relationships concerning race/ethnic subculture. The first is how racial/ethnic minority children compare to white children. The second is how girls within racial/ethnic groups compare to boys within the same group. Stratification and relative deprivation research, especially on patterns of cultural and social capital acquisition (Kalmijn and Kraaykamp, 1996), are well developed. They anticipate higher levels of political orientation for white children because white children are more readily exposed to Euro-American high-status culture. Consequently, although the numerical gap in cultural capital between white and black cohorts had been narrowing each decade since 1900 (Kalmijn and Kraaykamp, 1996: 29; but see also DiMaggio and Ostrower, 1990), the data show that white children are still advantaged.

Our second focus on how boys and girls vary within their own cultural categories speaks more directly to the unique cultural patterns of expected behavior for men and women channeled into childhood socialization. Hispanics and Asians share a cultural heritage stressing patriarchy 
(HardyFanta, 1993; Almquist, 1984; Chai, 1984). Compared to whites, we can expect the rate at which the Hispanic and Asian subcultures discount a girl's political orientation to be more robust. However, the case for Native Americans and blacks is not so straightforward, as both groups manifest "atypical expected behaviors for men and women" than those found in more general populations (Pierce, Avery, and Carey, 1977: 66-67). Black masculinity, long rendered "invisible" by slavery and subjugation, has undergone self-discovery in the last three decades (Franklin, 1994). Still, the higher rates of male absence from the home and the lingering effects of the historical subjugation of the black male and numerous other factors (see Staples, 1997) have prompted an increased role for black women (especially among the lower class) in those roles traditionally reserved for men (Pierce, Avery, and Carey, 1977: 66). As Lips (1995) notes (citing Lyson, 1986; Engram, 1980; Gump, 1975), however, "young black women have been found to be equally predisposed toward" female gender role attitudes (p. 142). While quite a bit of change has occurred since the coming of the Europeans, diverse, Native American communities have a standing tradition emphasizing a pivotal role for women in the public sphere (Almquist, 1995; 1984). For blacks and Native Americans then, there is no need to expect that cultural heritage would advantage boys in political socialization. Indeed, the reverse may well be the case. Thus, while theory provides clear expectations for Hispanics and Asians, such is not true for blacks and Native Americans.

The federal Family Educational Rights and Privacy Act of 1974 and the tender age of some of the children (as young as ten years old in the fourth grade) limited the kinds of family, attitudinal, and behavioral questions that $\mathrm{KV}$ could ask the children. However, data on several key control variables were obtained. Besides gender and race/ethnicity, the predictors parallel the four groups of stimuli that should generally influence the level of children's political orientation (see Kelly and 
Boutilier, 1978:190-8).

Socioeconomic status (SES) facilitates patterns of gender role specialization and differentiation (Sherkat and Blocker, 1994). SES influences gender role orientation in two ways. One is a direct impact predicated upon the value dispositions of upper- and middle-class families which encourage children to be autonomous and, ultimately, to develop a sense of efficacy (Sherkat and Blocker, 1994: 825). The other is a positive, indirect consequence orchestrated by the privileged educational position of upper- and middle-class families. Higher SES promotes educational attainment, a vital ingredient in nontraditional gender role development (Braungart, 1972). One item was used to gauge SES. It asked whether the family subscribed to or read a newspaper; people who subscribe to or read a newspaper are more likely to have a higher income and educational level than those who do not (Dominick, 1999; Fink, 1989; McLeod, Scheufele and Holbrook, 1999; Shoemaker \& Reese, 1991). ${ }^{5}$ Seventy-three percent $(\mathrm{N}=10,743)$ of the children reported that their families subscribed to or read a newspaper on a daily basis.

We also considered family political socialization, another equally strong derivative of SES. We used a question that asked whether political issues were discussed at home to measure family socialization. Sixty percent $(\mathrm{N}=8,845)$ of the children reported family discussion of politics at home. We expect children who reported family discussions of politics at home to exhibit higher levels of political orientation that comparable children who did not.

Children accumulate greater cultural capital as they age, although the content of that inventory may vary by gender due to gendered role socialization (Kalmijn and Kraaykamp 1996). Similarly, preadult political orientation progresses incrementally with age (see literature in Orum, et al., 1974). We utilized grade as a surrogate for age and specified an interaction term (gender*grade) 
allowing the effect of grade to vary by gender. (We diagnosed grade for non-linearity. The results prompted our use of the linear term.) Given research on regional differences in gender roles (Main, Gryski, and Schapiro, 1984), we also considered potential regional effects.

Finally, we needed to address the fact that the children in the data set were sampled from schools which operated the Kids Voting program. The program/school context could have exerted gains on children's orientation generally and girls' orientation in particular. Two sets of controls are employed to account for these potential effects, although the second taps the potential effect of KV more directly than the first. First, we incorporate the fixed effects feature to the analytical models (England, et al., 1988). Here, we entered dummies for each child's school of origin. By placing each child in his or her community, we are able to account for the potential effects of many factors not measured specifically in the study, particularly ecological school effects. Beyond that, since each teacher was responsible for implementing the curriculum, any potential impact of $\mathrm{KV}$ on the children would occur primarily through the teacher. The more the teacher talked about voting, the more likely children's consciousness will be raised. We specified as an independent variable a question that asked the children "how often their teacher talked in class about voting". Since girls tend to be better students than boys (see Younger and Warrington 1996) and that phenomenon could be evident in the data, we allowed the potential that any teacher/program effect could be gendered by constructing an interaction variable (gender*Teacher). ${ }^{6}$

Given that we do not follow these children into adulthood, we face the usual problem of political socialization studies: we cannot be certain how childhood political orientation will translate into the adult political orientation of these youngsters. 


\section{Empirical Results}

The first column of data in Table 1 for 'all respondents' indicates considerable variability in activity and opinion among the children. Not surprisingly, given current understanding of the reach of television in social life, children's use of the media for political information resulted in more television watching $(81 \%)$ than listening to the radio $(71 \%)$, reading newspapers $(57 \%)$ or reading magazines $(31 \%)$. About 76 percent of the children reported asking questions about voting at home or said they participated when political and social issues were debated at school. While 95 percent of the children thought voting was important, only 63 percent would like Kids Voting as part of what they learned in school, while only 55 percent actually cast a mock ballot on election day.

(Insert Table 1 about here)

The index of political orientation in Table 1 suggests that girls (mean=6.23) in the sample possess a significantly higher orientation toward politics than boys (mean=5.86). Moreover, except for the use of magazines for voting information (where boys and girls appeared evenly matched at approximately $31 \%$, respectively), girls display significantly higher percentages on every item explored in the analysis. In most cases, these differences are significant at the.001 level. That is, girls are significantly more likely than boys to see voting as important and to have actually cast a mock ballot. Girls are more likely to express interest in political activity at school or to ask politically relevant questions at home. Girls utilize the mass media to follow an election campaign to a greater degree than boys.

The second part of Table 1 compares boys and girls across three Census regions-South, Midwest, and West. Kids Voting was not used in Northeastern states in 1994, and therefore students 
from this region are not included in the data set. On the average, children from the Midwest (Mean=6.27) reported the highest levels of orientation, followed by those from the West (Mean=6.06) and then South (5.93). This pattern is consistent for both boys and girls. Moreover, girls scored higher than boys in each region, and the gap between boys and girls was largest in the South (Mean=-0.42). Overall, the data in Table 1 project not only the absence of a gap in favor of boys, but they actually suggest higher orientation levels for girls. ${ }^{7}$ Would this dynamic sustain once control factors are taken into account?

(Insert Table 2 about here)

Table 2 displays the results of multivariate analysis estimating potential differences between boys and girls. ${ }^{8}$ Model 1 introduces all predictors as single additive terms, while Models 2 and 3 allow the effect of gender to vary by grade and teacher. Model 3 introduces a variant specification using grade groupings 4-6, 7-9, and 10-12. The estimate for girls on Model 1 is positive and significant ( $\mathrm{r}=.28$ ). In Model 2, once the interaction terms are introduced, the positive additive effect for girls is not only reaffirmed, but the size of the estimated coefficient doubles $(r=.56)$. The interaction terms themselves are not significant. Since the single additive terms of grade and teacher are consistently positive and significant, any potential effects of these factors are not gender specific. The results of Model 3 using the grade groupings do not differ. Thus, controlling for grade, race, school, family SES, family socialization, and teacher, girls are estimated as more politically oriented when measured through the index. ${ }^{9}$

This differential firmly established, we now shift to the question of whether boys and girls vary in the individual items of orientation incorporated into the study. The interaction terms of gender/grade and gender/teacher are again specified in these equations (see Table 3). Except for the 
vote decision equation that indicates an insignificant, negative estimate for girls, all other equations portray consistently positive coefficients for girls; three of these estimates (Ask Questions at Home, Debate Issues at School, Whether Voting is Important) are significant. Only in the voting efficacy equation is the interaction of gender and teacher significant; the negative effect suggests that girls' support for the importance of voting diminished the more they heard from their teacher. All other equations suggest that any effects of teacher across these items are not gender specific. (See also the results of the single additive effects for teacher.) This means girls are not only more politically oriented than boys as measured by the index of orientation (Table 2), but girls are equally as political as boys in several of these individual items and actually surpass boys on three (Table 3).

(Table 3 about here)

We now turn to the hypotheses concerning race/ethnicity. First, we had predicted that white children would exhibit higher orientation than any other group. The results generally affirm that expectation: the coefficients in the specifications for the index (Table 2), estimating the effects of black, Asian, Hispanic, and Native American heritage, are all negative and significant. These negative signs intimate that, compared to white, any other heritage discounts children's averages significantly. Moreover, the coefficients for each group are remarkably consistent across the three specifications in Table 3 and constitute a basis for direct comparisons across subgroups. These coefficients posit that Native American children (-.25) exhibit a higher index than black (-.28), Asian (-.32), or Hispanic children (.37). Evidently, Hispanic heritage appears to discount the children's average the most.

We also asked whether race or ethnic heritage mediated any gender gap in orientation. Specifically, we hypothesized that boys and girls within particular racial/ethnic categories will differ 
in their levels of political orientation (The ability to have sufficiently large samples to allow separate estimations for Asian and Native American children is one of the innovative aspects of this research) To make our evaluation more manageable and to save space, we confine our discussion of multivariate analysis on gender differences across race/ethnic categories to the index of orientation.

Figure 1, which portrays racial/ethnic and gender differences, suggests, broadly, that girls possess significantly higher levels of orientation than boys across all racial/ethnic categories, although the intensity of the differences differs for particular groups. Overall, white girls scored higher (mean=6.4) on the index of orientation than any other group, followed by Native American (mean=6.1) and Asian (mean=6.0) girls. While white boys evinced the highest levels of orientation (mean=6.0) among all male groupings, Hispanic boys displayed the lowest score (mean=5.4). In all, Figure 1 suggests that the potential effect of culture on gender differences may not be as straightforward as might be anticipated. Consider this: white children scored higher on the index of orientation than Asian and Native American children; however, Asian and Native American girls scored higher than white boys.

(Insert Figure 1 about here)

(Insert Table 4 about here)

Table 4 displays the results of the multivariate analysis on the index of orientation, estimating potential gender differences within each racial/ethnic group. Without the interaction terms in the equation (Model 1), the estimate for all girls within each group is positive and significant, affirming that girls within each group are more politically oriented than boys. Although the interaction terms (Model 2) add little to the explanatory power of the models (and actually reduced the adjusted R-squared in the Asian case), their introduction adjusts the outcome noted for Model 1 somewhat. 
Turning first to the results for whites, specification of the interaction terms boosted white girls' advantage over white boys (from $r=.27$ to $r=.71$ ). The basic conclusion that white girls are better than white boys does not change. Conversely, except for Native Americans, Model 2 failed to replicate the advantage for girls noted in Model 1. At worse, boys and girls in these groups possess identical orientation levels.

Finally, we turn to the effects of the control variables throughout the analysis. The data indicate that family SES (as proxied by newspaper readership) is positively associated with children's orientation levels. This relationship obtains for all racial/ethnic groups. Regardless of racial/ethnic background, children, who reported political discussions at home are better off. The erect of the teacher differs somewhat. First, Table 2 suggests that all children benefitted from listening to their teacher. However, when the indicators are disaggregated in Table 3, the last column reporting the interaction effect of Gender/Teacher on the importance of voting indicates a negative effect for girls. In Table 4, the effect of teacher is gendered for white children with girls benefitting less the more they heard from their teacher. It is evident that black, Hispanic, Asian, and Native American children-boys and girls-all benefitted from hearing their teacher. ${ }^{10}$ Finally, grade-level (age) is positively related to orientation, although there are both a race and a gender intersection. Initially, Table 2 establishes that, regardless of sex, children's orientation increased with age. However, that may be true only for whites and Native Americans (see row for grade-level in Table 4). And then, boys and girls diverge on some factors of orientation (Table 3). Specifically, older girls appear less likely either to ask questions about politics at home or to seek political information in newspapers, while relying more on the radio for such information. 


\section{Summary And Implications}

The data and methodology we have brought to bear on the questions posed in this study, to our knowledge, are both the most expansive and conservative so far. Most previous studies relied exclusively on data from one state, some just on one locale. Our data covers 20 states and all the regions except the Northeast, which is less traditional on women's issues (Hill, 1981). Additionally, we surveyed more than 14,800 children. Although there have been suggestions on the potential confounding effects of race and ethnicity throughout this literature, our study identifies and estimates these effects at a level never before undertaken. The analysis also incorporates large numbers of Asian and Native American children. Finally, the fixed-effects feature we introduce into our analysis allows for comparative analysis while controlling for the effect of the environment.

We inquired whether boys and girls differed in their political orientations and whether race/ethnicity mediated any such differences. Drawing upon theories of child socialization and extant research on political orientation, we anticipated a narrowing gender gap still in favor of boys. However, we did not discover a narrowed gap in favor of boys. Instead, the girls in our data exhibited higher political orientation levels than boys. It is worth emphasizing that these are the only large-scale data showing girls to be more politically oriented than boys. Admittedly, these differences are small and statistical significance may have been aided by our large sample size. Given the status of the literature in this area, even if these differences had not reached the significance level, they would still have material and theoretical importance. For subgroups-whites and Native Americans-we found results greater for girls. For blacks, Hispanics, and Asians, we found differential advantages for girls, but those advantages were not replicated with full specification of 
the control variables. Even then, the results still indicated that boys were not superior to girls.

We need to address an aspect of our unique research design which could raise questions on the utility of these findings. The preceding analysis is based on data for children who participated in the Kids Voting program. The children's involvement in this school-sanctioned program could have influenced our findings, especially in light of the fact that girls tend to be higher achieving students than boys and may respond to their teachers' expectations more favorably than boys. In other words, is it conceivable that the patterns of girls' responses reflect their desire to please their teachers as opposed to measuring their level of interest and orientation? If this is the case, the patterns of orientations established in the study may not translate beyond $\mathrm{KV}$ and the school context.

To verify this factor, we relied on an ex post facto analysis of the effect of the teacher. As we have already noted, implementation of the KV curriculum was delegated to each teacher. Thus, whatever the children acquired from the project would be driven largely by their teacher. The results of the teacher effect reported throughout our analysis provide some evidence that the school context was not a major factor benefitting girls' orientation. First, the three equations in Table 2 show strong residual gender effects, although the single additive and interactive terms of teacher are specified. Those children whose teachers showed more interest in the project scored higher, but that was true for boys and girls equally and does not nullify, let alone explain, the residual gender effects.

Meanwhile, in Table 3, only in one model (voting important?) does the gender-teacher interaction attain significance. But then, that estimate was negative for girls. In Table 4, the genderteacher interaction was significant for white girls, but again that estimate was negative. In sum, wherever the gender-teacher interaction achieved significance, the estimate was negative. This could not be evidence of better performance or teacher-desirable responses by girls. While there is always a 
question of whether research findings can be extrapolated beyond the study group, there is no reason to anticipate that these results obtain only for this group of children.

Another aspect of our research design may help explain the differences between our findings and previous research. It pertains to the items we used in measuring political orientation. As we already noted, many of the earliest studies utilized political interest measures that may have been biased against finding girls interested in politics (see Bourque and Grassholtz, 1974). In discussing this literature, Iglitzin contends that "fixture socialization questionnaires need to broaden the conception of politics so that children will be asked questions dealing with political aspects of their own lives in home and school" $(1974,34)$. The items we used to measure orientation, unlike in previous studies, heavily feature actual participation (as opposed to what Bourque and Grassholtz complain are interpretive, abstract, and subjective notions of political interest). Actual participation items should provide greater affect/resonance and tap children's political interest more concretely. This factor, alone, might change the dynamics of children's responses to survey items. If this is the case, the choice of response items used in earlier studies could have exaggerated gender differences (also Welch, 1977).

Our findings also may result from the more egalitarian environment in the U. S. of the 1990s that may be producing changes in the political orientation of young girls. Girls can now observe female role models in such high profile government positions as Secretary of State, Supreme Court Justice, Attorney General, Governor, and Mayor. Outside government, women more commonly hold portfolios ranging from corporate executive to astronaut and clergy. These role models validate, complement and reinforce girls' evolving sense of citizenship. This paper lacks the longitudinal data needed to track how the change in the political environment would correlate with changes in the 
political orientation of young girls, but the findings are highly suggestive in this area.

Ultimately, gender-based political differences are integral to the challenge of citizenship for women (Saxonhouse, 1985). Only twenty years ago, political scientists still wrote about the natural proclivity of boys for politics and suggested that the presence of gender specific tendencies among children (i.e. the greater interest of boys in politics) would likely be a permanent constraint on women's political participation and leadership (see discussion in Bourque and Grossholtz, 1974). In turn, that research was brandished to foment the broader impression of politics as a man's game (Iglitzin, 1974). Our results---the gender effects, patterns of media use, and the effect of teacher-are at odds with the premise of immutable natural proclivities. If anything, the teacher effect raises fresh questions about the relevance of learning. It refocuses attention on the specter of lowering expectations and self-fulfilling prophesies in gender roles, embedded in popular culture and channeled into girls' socialization, as a relevant discourse on gender-based political differences. And if political socialization embodies vastly different content and behavioral norms for the sexes, one can certainly expect improvement in women's political profiles as these norms become more egalitarian. 


\section{FOOTNOTES}

1. Socialization has also been advanced as an explanation for women's occupational patterns (Kanter, 1977). Theorizing on the biological foundations of these differences is persistent, although the initial force of this line of inquiry has dissipated (Bourque and Grossholz, 1974). Kelly and Boutilier (1978, 12-25) outline this view, including works by Spencer, Mead, Spock, Freud, and Salzman. They present four biologically based theories operative here: 1) those which attribute special abilities because of anatomical, hormonal, or genetic differences; 2 ) those which emphasize reproductive vitality and differences; 3) those which rest on supposed natural instincts; and 4) those which stress the genius of exceptional individuals as the main forces of change.

2. The states and samples are: Alaska, 527; Arizona, 827; Arkansas, 820; California, 814; Colorado, 460; Florida, 722; Georgia, 992; Kansas, 1055; Kentucky, 513; Maryland, 1401; Michigan, 735; Minnesota, 943; Mississippi, 708; North Carolina, 806; Ohio, 533; South Carolina, 724; South Dakota, 881; Tennessee, 323; Texas, 438; Washington State, 633. Students come from 199 schools. 3. Of course, asked in a vacuum, this question would be inappropriate for these children. However, as part of a project they were very knowledgeable about, they understood the question.

4. Variable Coding. Did you ask questions about voting at home? Frequently or Occasionally=1; Never $=0$. How often did you watch things about voting on TV? Frequently or Occasionally=1; Never $=0$. How often did you read things in the newspaper about voting? Frequently or Occasionally= $1 ;$ Never $=0$. How often did you hear things about voting on the radio? Frequently or Occasionally $=1$; Never $=0$. How often did you read things about voting in magazines? Frequently or Occasionally $=1$; Never $=0$. When political and social issues are debated at your school, do you participate in those discussions? Frequently or Occasionally $=1$; Never $=0$. Would you like to have Kids Voting as part of 
what you learn in school the next time there is an election? Yes $=1 ; \mathrm{No}=0$. Did you go to the polls and vote on election day? Yes $=1 ; \mathrm{No}=0$. How important is it for people to vote on election day? Very or Somewhat Important $=1$; Not Very Important $=0$. How often does your family have political discussion at your home? Frequently or Occasionally=1; Never=0. How often did your teacher talk to you in class about voting? Frequently or Occasionally $=1$; Never $=0$. Does your family subscribe to or read a newspaper on a daily basis? Yes $=1 ; \mathrm{No}=0$. Gender: Female $=1$; Male $=0$. Grade level: Two levels of coding. Level One: actual grade level. Level Two (grouped dummies): grades 4-6; grades 7-9; and grades 10-12.

5. The relationship between socioeconomic variables and newspaper readership is well established in the communication literature. McLeod, Scheufele and Holbert (1999) reported that higher education and income levels have a positive relationship with newspaper readership. Dominick (1999) reported that education and age helps explain the decline in the percentage of adults reading one or more papers every day. Readership declined from about 80 percent in the early 1960s to about 60 percent in 1996; the most pronounced decline has occurred in the 18 to 29 and 30 to 44 age groups and among those who have not attended college. A 1998 national report commissioned by two newspaper trade associations reported that newspaper readership increases with education, household income, job responsibility, value of home and higher paying occupations (ASNE and NAA, 1998). According to the report, among college graduates, 77 percent reported reading a Sunday newspaper on a regular basis and 66 percent reported reading a daily newspaper. In contrast, of those with less than a high school education, 46 percent read a Sunday newspaper and 41 percent read a daily newspaper. Of people with household incomes of $\$ 75,000$ or more, 79 percent read Sunday papers and 71 percent read daily newspapers; in contrast, of people with household incomes of less than 
$\$ 40,000$, only 61 percent read Sunday newspapers and 52\% read daily newspapers.

6. Models are of the form: $\mathrm{I}=f(\mathrm{G}, \mathrm{X},,, \mathrm{Zj}$, where $\mathrm{I}$ is the index of political orientation; $\mathrm{G}$ is a dummy comparing girls to boys; $\mathrm{X}$ is a vector of other factors; and $\mathrm{Z}$ is the set of school dummies.

7. We compared the indices for the sexes across grade and for grade groupings 4-6, 7-9, and 10-12. Girls' indices were higher than boys' throughout. Except in the 11th grade, these differences were significant, with a slight attenuation of gender differences in the middle and higher grades.

8. Analysis of group composition in the population (children ages 10-19 as of July 1995, Statistical Abstract 1996) and the sample (data for Fall 1994) did not necessitate weighting: Nonwhite population $=29.6 \%$, sample $=30.5 \%$, Blacks $=13.7 \%$, sample $=15.4 \%$; Asians $=3.4 \%$, sample $=$ $3.9 \%$; Hispanics $=11.3 \%$, sample $=6.6 \%$; and Native Americans $=1.0 \%$, sample $=4.7 \%$.

9. The fixed effects feature introduced into the analysis did not allow for the specification of regional dummies. We re-estimated Model 2 (Table 3) with regional dummies, the South serving as the reference category. The analysis yielded the following equation, consistent with Table 2:

$\mathrm{POI}=3.33 * *+0.56 * *($ Female $)+0.06 * *($ Grade $)-0.34 * *($ Black $)-0.21 *($ Asian $)-0.34 * *$ $($ Hispanic $)-0.18 *($ N.Am. $)+1.24 * *($ Pol. Dis. $)+0.60 * *($ Newspaper $)+0.99 * *($ Teacher $)-0.01$ (Gender*Grade) -0.21 (Gender*Teacher) + 0.26**(Midwest) $+0.14 * *($ West $) .[* \mathrm{p}<.01 ; * * \mathrm{p}<.001]$ 10. We explored which interaction term discounted the additive effect of gender (Model 2) for blacks, Hispanics, and Asians. Both terms contribute to this result, although the terms themselves are not significant. Not allowing the effect of gender to vary by grade and teacher exaggerated the additive results for black, Hispanic, and Asian girls. Any gender differences across grade are not a significant explanation for gender differences in orientation within these groups. This dynamic has implications for socialization and group comparisons, although it does not alter our central findings. 


\section{REFERENCES}

Abramson, Paul R., and Ronald Inglehart. 1992. "Generational Replacement and Value Change in Eight West European Societies.” British Journal of Political Science 22 (April): 183-228.

Almquist, Elizabeth M. 1995. “The Experiences of Minority Women in the United States.” Pp. 573606 in Jo Freeman, ed., Women: A Feminist Perspective. Palo Alto, California: Mayfield.

—. 1984. "Race and Ethnicity in the Lives of Minority Women." Pp. 423-53 in Jo Freeman, ed., Women: A Feminist Perspective. Palo Alto, California: Mayfield.

American Society of Newspaper Editors and The Newspaper Association of America (1998). "Leveraging newspaper assets." New York: American Society of Newspaper Editors.

Bennett, Linda L. M., and Stephen Earl Bennett. 1989. "Enduring Gender Differences in Political Interest.” American Politics Quarterly 17 (January): 105-22.

Bourque, Susan C., and Jean Grossholtz. 1974. "Politics as Unnatural Practice: Political Science Looks at Female Participation." Politics and Society 4 (Winter): 225-66.

Boykin, Wade A., and Constance M. Ellison. 1995. "The Multiple Ecologies of Black Youth Socialization.” Pp. 93-128 in Ronald Taylor, ed., African-American Youth. Conn.: Praeger.

Bozeman, Barry, Sandra Thornton, and Michael McKinney. 1977. "Continuity and Change in Opinions About Sex Roles.” Pp. 38-65 in Marianne Githens and Jewel L. Prestage, eds., A Portrait of Marginality. New York: Longman.

Braungart, Richard G. 1972. "Family Status, Socialization and Student Politics: A Multivariate Analysis." American Journal of Sociology 77 (July): 108-30.

Carroll, Susan J. 1994. Women as Candidates in American Politics. Ind.: Indiana University Press. Carroll, Susan J., and Linda M. G. Zerilli. 1993. "Feminist Challenges to Political Science.” In Ada 
W. Finifter, ed., Political Science: The State of the Discipline II. Washington, DC: The American Political Science Association.

Chai, Alice Y. 1984. Toward A Holistic Paradigm For Asian American Women's Studies. Unpublished Working Paper \#51, Michigan State University.

Clinton, Catherine. 1999. The Other Civil War. New York: Hill and Wang.

Conover, Pamela-Johnston. 1988. "Feminists and the Gender Gap." Journal of Politics 50 (November):985-1010.

Conway, Margaret, David Ahern, and Gertrude Steuernagel. 1995. Women and Public Policy: A Revolution in Progress. Washington, DC: Congressional Quarterly Press.

Darcy, Robert, Susan Welch, and Janet Clark. 1994. Women, Elections, and Representation. Lincoln: University of Nebraska Press.

DiMaggio, Paul, and Francie Ostrower. 1990. "Participation in the Arts by Black and White Americans." Social Forces 68: 753-78.

Dominick, J. R. (1999). The Dynamics of Mass Communication. New York: McGraw-Hill.

England, Paula, George Farkas, Barbara Kilbourne, and Thomas Dou. 1988. "Explaining Occupational Sex Segregation and Wages: Findings From a Model with Fixed Effects.” American Sociological Review 53 (August): 544-58.

Engram, E. 1980. "Role Transition in Early Adulthood.” In La Frances Rogers-Rose, ed., The Black Woman. California: Sage.

Fink, Conrad C. (1989, March). "How newspapers should handle upscale/downscale conundrum." Presstime, $40-41$.

Franklin, Clyde W. 11. 1994. “Men's Studies, the Men's Movement, and the Study of Black 
Masculinities." Pp. 3-19 in Richard G. Majors and Jacob U. Gordon, eds., The American Black Male. Chicago: Nelson-Hall Publishers.

Gerber, Ellen, Jan Felshin, Pearl Berlin, and Wanum Wyrich. 1974. The American Woman in Sport Reading, MA: Addison-Wesley.

Gilligan, Carol. 1982. In a Different Voice. Cambridge: Harvard University Press.

Githens, Marianne, and Jewel L. Prestage. 1977. "Introduction.” Pp. 3-10 in Marianne Githens and Jewel L. Prestage, eds., A Portrait of Marginality. New York: Longman.

Greeley, Andrew. 1975. “A Model For Ethnic Political Socialization.” American Journal of Political Science 19(May):187-206.

Greenstein, Fred 1. 1961. “Sex-Related Political Differences in Childhood.” Journal of Politics 23 (2):353-71.

Gump, Janice, 1975. “A Comparative Analysis of Black and White Women's Sex-Role Attitudes.” Journal of Consulting and Clinical Psychology 43: 858-63.

Hardy-Fanta, Carol. 1993. Latina Politics, Latino Politics. Philadelphia: Temple University Press. Hartmann, Susan. 1989. From Margin to Mainstream. Philadelphia: Temple University Press.

Henry, William A. III. 1991. “Tying the Boy Scouts in Knots.” Time 137 (November 26):65-66.

Hill, David B. 1981. "Political Culture and Female Representation." Journal of Politics 43 (February): 151-68.

Iglitzin, Lynne B. 1974. “The Making of the Apolitical Woman.” Pp. 25-53 in Jane S. Jaquette, ed., Women in Politics. New York: John Wiley \& Sons.

Jackson, James S., Wayne R. McCullough, and Gerald Gurin. 1997. "Family, Socialization Environment, and Identity Development in Black Americans.” Pp. 251-66 in Harriette P. 
McAdoo, ed., Black Families. Thousand Oaks, Cal.: Sage.

Kahn, Karen (ed.). 1995. Frontline Feminism 1975-1995. San Francisco: Aunt Lute Books.

Kalmijn, Matthijs and Gerbert Kraaykamp. 1996. "Race, Cultural Capital, and Schooling: An Analysis of Trends in the United States.” Sociology of Education 69 (January): 22-34.

Kanter, Rosabeth M. 1977. Men and Women of the Corporation. New York: Basic Books.

Kelly, Rita M., and Mary Boutilier. 1978. The Making of Political Women. Chicago: Nelson-Hall.

Kirkpatrick, Jeanne. 1974. Political Women. New York: Basic Books.

Langer, Cassandra L. 1996. A Feminist Critique. New York: HarperCollins.

Lips, Hilary M. 1995. “Gender-Role Socialization.” Pp. 128-48 in Jo Freeman, ed., Women: A Feminist Perspective. Palo Alto, California: Mayfield.

Lyson, Thomas A. 1986. "Race and Sex Differences in Sex Role Attitudes of Southern College Students." Psychology of Women Quarterly 10 (4): 421-28.

Main, Eleanor, Gerald Gryski, and Beth Schapiro. 1984. "Different Perspectives: Southern State Legislatures’ Attitudes about Women in Politics.” Social Science Journal 21(1):21-28.

Massey, D. S., and N.A. Denton. 1993. American Apartheid MA: Harvard University Press.

McLeod, J. M., Scheufele, D. A. \& Holbert, R. L. (1999). Crime or community? The impact of changes in local newspaper content on circulation. Paper presented at the annual convention of the International Communication Association, San Francisco, CA.

Orum, Anthony, Robert Cohen, Sherri Grasmuck, and Amy Orum. 1974. "Sex, Socialization, and Politics." American Sociological Review 39 (April): 197-209.

Owen, Diana, and Jack Dennis. 1988. “Gender Differences in the Politicization of American 
Children." Women \& Politics 8 (2):23-43.

Peters, Marie F. 1997. "Historical Note: Parenting of Young Children in Black Families." Pp. 167-82 in Harriette P. McAdoo, ed., Black Families. Thousand Oaks, Cal.: Sage.

Pierce, John C., William P. Avery, and Addison Carey, Jr. 1977. "Sex Differences in Black Political Beliefs and Behavior.” Pp. 66-74 in Marianne Githens and Jewel L. Prestage, eds., A Portrait of Marginality. New York: Longman,

Rapoport, Ronald B. 1982. "Sex Differences in Attitude Expression: A Generational Explanation." Public Opinion Quarterly 46 (Spring): 86-96.

Rapoport, Ronald B. 1985. "Like Mother, Like Daughter: Intergenerational Transmission of DK Response Rates.” Public Opinion Quarterly 49 (Summer): 198-208.

Sapiro, Virginia. 1983. The Political Integration of Women. Urbana: University of Illinois Press. Sapiro, Virginia. 1986. Women in American Society. Mountain View, CA: Mayfield.

Saxonhouse, Arlene W. 1985. Women in the History of Political Thought: Ancient Greece to Machiavelli. New York: Praeger.

Schlozman, L. Kay, Nancy Burns, Sidney Verba, and Jesse Donahue. 1995. “Gender and Citizen Participation.” American Journal of Political Science 39 (May): 267-93.

Sherkat, E. Darren, and T. Jean Blocker. 1994. "The Political Development of Sixties’ Activists.” Social Forces 72 (March): 821-42.

Shoemaker, Pamela J. and Stephen D. Reese (1991). Mediating the message: Theories of influences on mass media content. White Plains NY: Longman

Staples, Robert. 1997. “An Overview of Race and Marital Status.” Pp. 269-83 in Harriette P. McAdoo, ed., Black Families. Thousand Oaks, Cal.: Sage. 
Tatum, Beverly D. 1997. “Out There Stranded? Black Families in White Communities.” Pp. 214-33 in Harriette P. McAdoo, ed., Black Families. Thousand Oaks, Cal.: Sage.

Thomas, Sue. 1994. How Women Legislate. New York: Oxford University Press.

Verba, Sidney, Kay Lehman Schlozman, and Henry E. Brady. 1995. Voice and Equality: Civic Voluntarism in American Politics. MA.: Harvard University Press.

Welch, Susan. 1977. "Women as Political Animals?" American Journal of Political Science 21 (November): 711-30.

Welch, Susan. 1978. "Recruitment of Women to Public Office: A Discriminant Analysis." Western Political Quarterly 31 (September): 372-80.

Welch, Susan, and Lee Sigelman. 1989. “A Black Gender Gap?” Social Science Quarterly 70 (March): 120-3 3 .

Younger, Mike, and Molly Warrington. 1996. "Differential Achievement of Girls and Boys at GCSE.” British Journal of Sociology of Education 17(September):299-313. 